\title{
Reseña Bibliográfica: Stollberg-Rilinger, B. (2018). The Holy Roman Empire. A Short History. Princeton: Princeton University Press. 164 pp.
}

\author{
Palabras clave: Sacro Imperio - Edad Moderna - Historia Constitucional
}

Keywords: Holy Roman Empire - Modern Early Age - Constitutional History

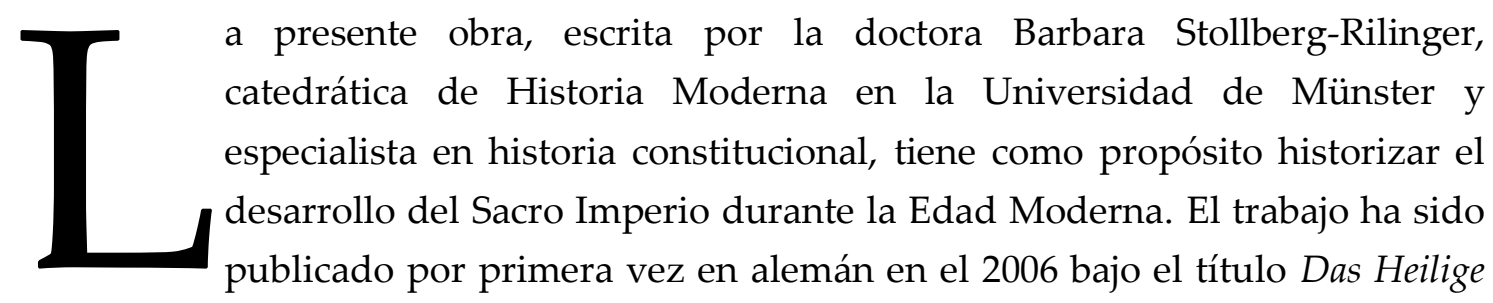

Römische Deutscher Nation: Vom Ende des Mittelalters bis 1806 y en el 2018 fue traducido al inglés por el profesor Yair Mintzker. Este estudio se abocó al periodo que va desde fines del siglo XV hasta principios del siglo XIX. La necesidad de un trabajo introductorio de síntesis, tal como resulta en este caso, parte del interés que generó la peculiar naturaleza del Sacro Imperio en los historiadores del siglo XIX y XX, así como la del público en general. En este sentido, el lente del Estado-Nación ha propugnado una imagen distorsionada de esta entidad política, caracterizándola como una anomalía dentro del relato teleológico estatal y nacionalista.

Precisamente, el mérito de Stollberg-Rilinger radica en su propósito de distinguir y caracterizar a cada uno de los elementos que dieron vida a la estructura política que sostuvo a un Sacro Imperio que aglomeró a un mosaico plurinacional de estados menores. Los dos primeros capítulos resultan una breve pero puntual explicación del origen y del por qué esta entidad llevaba el nombre de Holy Roman Empire (Sacro Imperio Romano). También caracteriza a sus actores sociales y políticos, resaltando aquellos lazos feudales jerárquicos (muchas veces superpuestos) que mantuvieron unidos a cada uno de ellos con la figura que daba articulación y sentido a todo el sistema: el Emperador. Sin embargo, a pesar de cargar con tamaña responsabilidad, este príncipe carecía de un poder "absoluto", ya que, si bien se reservaba derechos tales como el ennoblecimiento, lo cierto es que el signo político distintivo del Imperio, respecto a otras monarquías, fue el consenso entre cada una de sus partes. Esto se debió no tanto a una concepción democrática del poder, sino más bien a la posesión y ejercicio, por parte del emperador, de una cuota de poder suficiente como para equilibrar las relaciones entre señores de distinta envergadura. Por ello, se lo concibe como una "unión de sujetos", reglamentada 
por algunas instituciones o leyes comunes, tales como la Dieta Imperial o la Bula de Oro. Sin embargo, esta tendencia era la excepción más que la regla.

El tercer capítulo es una explicación de cómo se cimentó el sistema político, base de la organización del Sacro Imperio a lo largo de la Edad Moderna, el que sufrió algunas modificaciones a lo largo de su desarrollo histórico. A partir del siglo XV, las necesidades particulares y coyunturales de estabilizar las relaciones políticas y económicas del Imperio posibilitaron que, bajo la tutela del emperador Maximiliano I de Habsburgo, se pudiese establecer un status quo lo suficientemente duradero, pero al mismo tiempo flexible. Esto en definitiva posibilitó la existencia misma de la entidad imperial. Ejemplo de ello fue la sanción de la llamada "paz perpetua", en la Dieta de Worms de 1495, la instauración de la Cámara Imperial -que rápidamente rivalizó con el Consejo Áulico Imperial- o la creación de los Círculos Imperiales.

Tanto el cuarto como el quinto capítulo tratan de cómo el Imperio, a pesar de sus problemas internos (estallido de la reforma luterana y la consiguiente confesionalización) pudo sobrevivir gracias a una serie de resortes institucionales y elementos pilares (poder de la dinastía Habsburgo, el sistema de alianzas entre príncipes y sus respectivas políticas de relación) hasta el estallido de la Guerra de los Treinta Años en 1618. De esta forma, se analiza el periodo abierto desde la dieta de Worms de 1521, a la que Lutero asistió en presencia de Carlos V, pasando por la Paz de Augsburgo de 1555, que, si bien no pudo evitar la fragmentación religiosa, pudo mantener la unidad política. El estudio se extiende hasta el estallido del conflicto en 1618, momento en el que el poder territorial de cada señor se hallaba fortalecido, así como la radicalización confesional.

Por su parte, el sexto y séptimo capítulo proponen un análisis de la conflagración conocida como la Guerra de los Treinta Años, iniciada en 1618 hasta la firma de la paz de Westfalia en 1648, y de cómo dicho enfrentamiento trastocó el orden político del Sacro Imperio. Stollberg-Rilinger sostiene que el elemento confesional jugó un papel muy importante, aunque no fue el único factor, ya que se entremezcló con otras cuestiones, tales como las reticencias de los señores protestantes bohemios ante el intento de fortalecimiento de la autoridad real por parte del rey Fernando II (también Sacro Emperador). A partir de ello, el conflicto se "internacionalizó" debido al juego de alianzas que sendos príncipes adscribían con reinos del exterior, así como entre miembros imperiales. Al final de este conflicto la imagen imperial estuvo condicionada por un complejo juego de equilibrio confesional y político, que, si bien reconocía la autoridad del Emperador, en realidad el consenso y negociación entre los príncipes debía ser el principio regulador. Este pacto tácito se respetaría a través de la Dieta imperial. Fue así como el contexto post-Westfalia inauguró un lento proceso de debilitamiento de la idea de comunidad política del Sacro Imperio. Sin embargo, esto no sucedió tan pronto, ya que fue ralentizado por la política de integración y patrocinio que implementó Leopoldo I (1640-1705) durante su reinado, a través de la hábil utilización del Consejo Áulico. 
Tras el final de este interregno (proseguido por los emperadores José I y Carlos VI), a partir de 1740 se iniciaría un periodo de polarización entre aquellos centros de poder más gravitantes (Prusia-Brandemburgo y Austria-Hungría, quienes además competían entre sí) y aquellos más débiles. La primera división, además, agregaba el elemento confesional como línea divisoria: un norte protestante, encabezado por Prusia por un lado, y, por otro lado, el sur dominado por el peso de la católica Austria. Fue así como durante la traumática sucesión de María Teresa, hija de Carlos VI, la guerra fue una ocasión ideal para la manifestación de esta división. Esta tendencia prosiguió hasta el reinado de José II (1741-1790).

El definitivo final del Sacro Imperio se produjo a inicios del siglo XIX, cuando en la coyuntura de las guerras napoleónicas el emperador Francisco II abdicó la corona imperial y disolvió las obligaciones feudales que mantenían los miembros imperiales hacia su persona. Además del factor de la guerra contra Francia, el final se produjo por el recrudecimiento de la polarización entre Prusia-Brandemburgo y Austria, quienes priorizaron sus respectivos intereses patrimoniales. Esta situación de facto se formalizó en la paz de Lunéville (1801) y se terminó de efectivizar en agosto de 1806.

La autora concluye que el Imperio, entendido como una asociación política defensiva, no conformó en ningún momento un cuerpo legal codificado, sino una serie de leyes, derechos y privilegios particulares. Esto se debía justamente a la naturaleza del mismo Imperio, ya que su estructura respondía a una organización jerarquizada a través de lazos personales entre diferentes señores, cuya cúspide era ocupada por el Emperador y los electores. A pesar de ello, este nunca desempeñó el papel de soberano "absoluto" debido al intrincado sistema de fidelidades, donde los vasallos del caballero más pequeño debían obediencia a este y no directamente al Emperador. De esta forma, el Imperio sobrevivió a lo largo de la Modernidad gracias a su capacidad para reorganizarse ante diferentes episodios traumáticos, sorteándolos con notable flexibilidad. Sin embargo, la coyuntura política de principios del siglo XIX fue un golpe letal a una integridad y equilibrio ya para entonces bastante endeble.

En términos generales, la obra supone una útil y actualizada herramienta para todo aquel interesado en introducirse en el estudio de la política del Sacro Imperio durante la Edad Moderna. La autora explica de manera clara y convincente cómo esta unidad política sorteó los riesgos de desintegración valiéndose del consenso y la negociación como elementos prioritarios; haciendo uso de varios resortes de integración. Estas cuestiones resultan valiosas para poder destacar la naturaleza de las ideas y el ejercicio de la política durante el Antiguo Régimen, sin recurrir a la noción de absolutismo. Otro punto clave es la consideración del elemento confesional, como una variable sumamente relevante para entender este juego político. En otras palabras, es una obra de síntesis que merecería traducirse al español, ya que supondría un gran aporte a la historiografía en dicha lengua, sobre todo para los estudiantes universitarios.

A pesar de estos puntos fuertes, la obra, quizás en su afán de resumir tanto caudal de datos y hechos, no profundiza demasiado en el elemento dinástico, especialmente en la 
política que mantuvieron los Habsburgo austríacos con la corte hispana. Por otro lado, adolece de mapas detallados, así como de documentos destinados para su análisis, una carencia remarcable, si se tiene en cuenta que su contenido es de carácter divulgativo, entre un público culto.

Javier Hipólito Villanueva

Universidad Nacional de Salta javierhvillanueva@gmail.com 